\title{
PROFIL KEMAMPUAN MAHASISWA DALAM MENYELESAIKAN SOAL HOTS DI JURUSAN PENDIDIKAN FISIKA UNIVERSITAS PAPUA
}

\author{
Irfan Yusuf ${ }^{1}$, Sri Wahyu Widyaningsih ${ }^{2}$ \\ Program Studi Pendidikan Fisika Universitas Papua ${ }^{1,2}$ \\ Email: i.yusuf@unipa.ac.id ${ }^{1}$, s.widyaningsih@unipa.ac.id ${ }^{2}$
}

\begin{abstract}
Abstrak
Penelitian ini bertujuan untuk mengetahui kemampuan mahasiswa dalam menyelesaian soal Higher Order Thinking Skills (HOTS) menurut taksonomi Bloom hasil revisi yaitu C4, C5, dan C6. Pengujian dilakukan pada 22 orang mahasiswa di Program Studi Pendidikan Fisika Universitas Papua Semester Genap 2016-2017 yang mengontrak mata kulah Laboratorium Sekolah. Instrumen yang digunakan dalam penelitian ini adalah soal pada materi tekanan yang terdiri dari 25 soal pilihan ganda. Penelitian ini merupakan penelitian deskriptif dengan menggunakan pendekatan kuantitatif melalui pemodelan Racsh. Hasil penelitian menunjukkan bahwa rata-rata nilai mahasiswa dalam menyelesaikan soal C4 yaitu 53,18, soal C5 yaitu 52,27 sedangkan soal C6 yaitu 68,83 dengan Rerata 57,27 \pm SD 16,70 berada pada kategori baik. Pemodelan Rasch menunjukkan bahwa soal nomor 14 dan nomor 7 yaitu soal C4 (analisis) memiliki tingkat kesukaran paling tinggi untuk diselesaikan mahasiswa. Soal nomor 5 dan nomor 6 yaitu C6 (mencipta) memiliki tingkat kesulitan paling rendah. Hasil penelitian menunjukkan bahwa kemampuan mahasiswa dalam menyelesaikan soal tingkat tinggi masih rendah terutama pada soal C4 dan C5.
\end{abstract}

Kata-kata kunci: Higher Order Thinking Skill (HOTS), menganalisis, mengevaluasi, dan mencipta

\section{PROFILE OF SKILLS STUDENTS IN RESOLVING PROBLEMS HOTS IN THE DEPARTMENT OF PHYSICS EDUCATION UNIVERSITY OF PAPUA}

\author{
Irfan Yusuf ${ }^{1}$, Sri Wahyu Widyaningsih ${ }^{2}$ \\ Program Studi Pendidikan Fisika Universitas Papua ${ }^{1,2}$ \\ Email: i.yusuf@unipa.ac.id ${ }^{1}$, s.widyaningsih@unipa.ac.id ${ }^{2}$
}

\begin{abstract}
This study aims to determine the ability of students to solve the problem of Higher Order Thinking Skills (HOTS) according to Bloom's taxonomy revisions are C4, C5, and C6. The test was conducted on 22 students in the Department of Physics Education, University of Papua in 2016-2017 who contracted Laboratory School courses. The instrument used in this study is a matter of pressure material consisting of 25 multiple choice questions. This research is a descriptive research using quantitative approach through racsh modeling. The results showed that the average value of students in solving the problem of C4 is 53.18, about C5 is 52.27 while the problem of C6 is 68.83 with a mean of $57.27 \pm S D$ 16.70. Rasch modeling shows that question number 14 and number 7 that is about C4 (analysis) has the highest difficulty level for students to complete. Problem number 5 and number 6 is C6 (create) have the lowest difficulty level. The results showed that the students' ability in solving high level is still low, especially in the matter of $\mathrm{C} 4$ and $\mathrm{C} 5$.
\end{abstract}

Keywords: Higher Order Thinking Skill (HOTS), analyze, evaluate, and create 


\section{PENDAHULUAN}

Proses evaluasi dalam pembelajaran sangat penting dilakukan untuk mengetahui apakah tujuan pembelajaran telah tercapai atau tidak. Evaluasi dapat dilakukan selama pembelajaran melalui observasi kegiatan peserta didik selama belajar, maupun evaluasi setelah pembelajaran dilaksanakan. Evaluasi merupakan proses mengumpulkan data atau hasil kerja peserta didik sebagai sarana untuk mengamati sejauh mana tujuan pembelajaran telah tercapai (Suharsimi, 2009).

Evaluasi pembelajaran dapat dilakukan melalui penggunaan berbagai macam instrumen tes berupa soal-soal maupun instrumen non tes berupa angket dan lembar observasi. Teknik evaluasi yang sering digunakan terutama untuk mengukur ketercapaian tujuan pembelajaran yaitu evaluasi berupa soal tes. Tes berfungsi untuk mengukur berbagai perkembangan yang telah dicapai oleh peserta didik setelah mengikuti kegiatan pembelajaran selama rentang waktu tertentu (Sudijono, 2013). Pengukuran kemampuan peserta didik selama pembelajaran terbagi kedalam tiga aspek penilaian yaitu ranah kognitif, afektif, dan psikomotorik.

Pengukuran ranah kognitif biasanya dilakukan melalui intrumen tes seperti soal essai, pilihan ganda, isian singkat dan lainlain. Ranah kognitif mengurutkan keahlian berpikir sesuai dengan tujuan yang diharapkan. Proses berpikir menggambarkan tahap berpikir yang harus dikuasai oleh peserta didik agar mampu mengaplikasikan teori kedalam perbuatan. Menurut taksonomi Bloom hasil revisi, keterampilan berpikir pada ranah kognitif terbagi menjadi enam tingkatan yaitu: mengingat (C1), memahami (C2), mengaplikasikan (C3), menganalisis (C4), mengevaluasi (C5), dan mencipta/mengkreasi (C6) (Retno, 2011). Tiga level pertama (terbawah) yaitu C1, C2 dan C3 merupakan Lower Order Thinking Skills (LOTS), sedangkan tiga level berikutnya yaitu C4, C5, dan C6 merupakan tipe Higher Order Thinking Skills (HOTS).

Instrumen tes yang biasanya digunakan di sekolah-sekolah maupun perguruan tinggi biasanya hanya mencakup ranah kognitif $\mathrm{C} 1$ sampai $\mathrm{C} 4$, sehingga keterampilan berpikir tingkat tinggi mahasiswa kurang dikembangkan. Kemampuan dalam menyelesaikan soal HOTS sangat penting dalam mengembangkan kemampuan berpikir kritis mahasiswa.

Soal HOTS disusun berdasarkan tingkatan ranah $\mathrm{C} 4, \mathrm{C} 5$, dan $\mathrm{C} 6$ yang dirumuskan dalam indikator soal. Soal HOTS dapat disajikan dalam bentuk soal pilihan ganda, essai dan lain-lainnya. Untuk itu perlu dilakukan penelitian mengenai keterampilan berpikir tingkat tinggi di Program Studi Pendidikan Fisika Fakultas Keguruan dan Ilmu Pendidikan Universitas Papua. Pengukuran kemampuan tersebut 
dilakukan dengan pemberian soal HOTS. Penelitian ini bertujuan untuk mengukur kemampuan mahasiswa dalam menyelesaian soal HOTS menurut taksonomi Bloom hasil revisi yaitu katagori ranah $\mathrm{C} 4, \mathrm{C} 5$, dan $\mathrm{C} 6$.

\section{METODE PENELITIAN}

Penelitian ini merupakan penelitian deskriptif dengan menggunakan pendekatan kuantitatif melalui pemodelan Racsh. Hasil analisis secara umum dapat dilihat pada program Winsteps dengan mengunakan output tabels 1. Variabel Map. Pengujian dilakukan pada 22 orang mahasiswa di Program Studi Pendidikan Fisika Universitas Papua Semester Genap 20162017 yang mengontrak mata kulah Laboratorium Sekolah. Instrumen yang digunakan dalam penelitian ini adalah soal pada materi tekanan yang terdiri dari 25 soal pilihan ganda. Tabel 1 menunjukkan kisikisi soal yang digunakan dalam penelitian.

Tabel 1. Kisi-Kisi Soal

\begin{tabular}{|c|c|c|c|c|}
\hline \multicolumn{2}{|l|}{ Indikator } & \multirow{2}{*}{$\begin{array}{c}\begin{array}{c}\text { Ranah } \\
\text { Kognitif }\end{array} \\
\text { C4 }\end{array}$} & \multirow{2}{*}{$\begin{array}{l}\text { Kata Kerja Operasional } \\
\text { Analisis }\end{array}$} & \multirow{2}{*}{$\begin{array}{c}\text { No Soa } \\
1\end{array}$} \\
\hline Mengkreasikan & konsep & & & \\
\hline tekanan & & $\mathrm{C} 4$ & Menghubungkan & 2 \\
\hline & & C5 & Menilai & 3 \\
\hline & & C5 & Menyimpulkan & 4 \\
\hline & & C6 & Merancang & 5 \\
\hline & & C6 & Merancang & 6 \\
\hline Mengkreasikan & konsep & $\mathrm{C} 4$ & Analisis & 7 \\
\hline \multirow{5}{*}{ tekanan hidrostatis } & & $\mathrm{C} 4$ & Analisis & 8 \\
\hline & & C5 & Menilai & 9 \\
\hline & & $\mathrm{C} 5$ & Menilai & 10 \\
\hline & & $\mathrm{C} 5$ & Memilih & 11 \\
\hline & & C6 & Merancang & 12 \\
\hline Mengkreasikan & konsep & $\mathrm{C} 4$ & Analisis & 13 \\
\hline \multirow[t]{6}{*}{ Hukum Pascal } & & $\mathrm{C} 4$ & Analisis & 14 \\
\hline & & $\mathrm{C} 5$ & Menaksir & 15 \\
\hline & & C6 & Merancang & 16 \\
\hline & & C6 & Merancang & 17 \\
\hline & & $\mathrm{C} 4$ & Analisis & 18 \\
\hline & & $\mathrm{C} 4$ & Analisis & 19 \\
\hline Mengkreasikan & konsep & $\mathrm{C} 4$ & Analisis & 20 \\
\hline \multirow{5}{*}{\multicolumn{2}{|c|}{ Hukum Archimedes }} & $\mathrm{C} 4$ & Analisis & 21 \\
\hline & & $\mathrm{C} 5$ & Memperjelas & 22 \\
\hline & & C5 & Menyimpulkan & 23 \\
\hline & & C6 & Mengajukan & 24 \\
\hline & & C6 & Memadukan & 25 \\
\hline
\end{tabular}


Penilaian tingkat pemahaman mahasiswa dilakukan berdasarkan pengkatagorian sebagaimana menurut (Riduwan, 2011) pada tabel 2.

Tabel 2. Kriteria Interpretasi Skor

\begin{tabular}{cc}
\hline Persentase (\%) & Kriteria \\
\hline $0-25$ & Sangat Kurang \\
$26-50$ & Kurang \\
$51-75$ & Baik \\
$76-100$ & Sangat Baik \\
\hline
\end{tabular}

\section{HASIL DAN PEMBAHASAN}

Hasil penelitian menunjukkan bahwa rata-rata nilai mahasiswa dalam menyelesaikan soal $\mathrm{C} 4$ (menganalisis) yaitu 53,18 , soal C5 (menilai) yaitu 52,27 sedangkan soal C6 (mengkreasi) yaitu 68,83 dengan rata-rata keseluruhan yaitu 57,27 \pm SD 16,70 atau kategori baik sebagaimana terlihat pada Gambar 1.

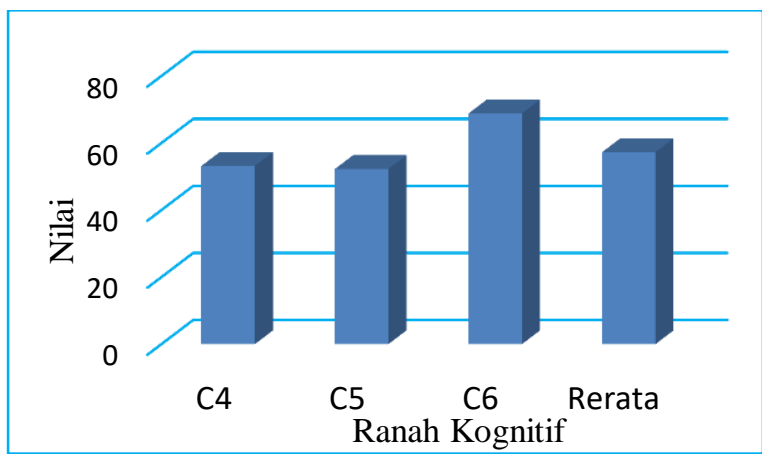

Gambar 1. Nilai Mahasiswa pada Setiap Ranah Kognitif Bloom

Gambar 1 menunjukkan bahwa soal C4 dan C5 memiliki skor yang relatif sama yaitu berkisar 50, sedangkan soal C6 memiliki skor berkisar 60 lebih tinggi dibandingkan dengan soal $\mathrm{C} 4$ dan $\mathrm{C} 5$. Hal tersebut menunjukkan bahwa mahasiswa lebih cenderung mudah dalam mengkreasikan konsep yang dipelajari dibandingkan menganalisis dan menilai. Beberapa faktor yang mempengaruhi hasil tersebut antara lain sebelum diadakan tes, mahasiswa mengikuti perkuliahan laboratorium sekolah melalui pembelajaran model PjBL berbasis alat peraga sederhana. Pembelajaran PjBL menuntut kreativitas mahasiswa untuk berkreasi merancang alat peraga sederhana sesuai dengan target proyek yang telah disepakati bersama. Penggunaan model pembelajaran yang tepat akan berpengaruh terhadap kemampuan kognitif peserta didik. Sebagai mana menurut (Pangkali, Sinon, \& Widyaningsih, 2016) bahwa melalui penggunaan model pembelajaran yang berorintasi aktivitas peserta didik dapat meningkatkan hasil belajar kognitif peserta didik.

Berdasarkan penilaian kemampuan mahasiswa dalam menyelesaikan soal HOTS, masih terdapat beberapa yang kesulitan dalam mengerjakan soal yang diberikan. Salah satu penyebab mahasiswa kesulitan dalam menjawab soal HOTS yaitu bentuk soal yang berupa pilihan ganda. Sejalan dengan hasil penelitian (Sophiaraja, 2017) menyatakan bahwa hal yang menyebabkan masih rendahnya skor HOTS dipengaruhi oleh bentuk instrumen yang sebagian besar berjenis tes pilihan ganda, sehingga membuat jawaban peserta didik menjadi terbatas dan kurang memfasilitasi mereka untuk mengutarakan pendapat, mengungkapkan dengan bebas apa yang 
mereka ketahui dan solusi seperti apa yang hendak mereka berikan untuk menyelesaikan permasalahan yang ada pada soal.

Peserta didik perlu diberikan kebebasan dalam mengkreasikan berbagai penyelesaian soal HOTS yang diberikan. Orientasi aktivitas peserta didik dalam pembelajaran sangat penting dan tidak semata-mata hanya menjelaskan isi dari bahan ajar yang ada. Pemilihan bahan ajar yang relevan juga perlu diperhatikan karena kebanyakan permasalahan yang ada hanya bersifat hafalan atau ranah LOTS. Perlu dikembangkan perangkat pembelajaran berupa buku ajar yang menuntut kreativitas peserta didik untuk mengkaji secara mendalam materi pelajaran yang mencakup ranah HOTS. Sebagaimana menurut (Tanujaya, Prahmana, \& Mumu, 2017) bahwa rendahnya kemampuan peserta didik dalam menyelesaikan soal yang menuntut keterampilan berpikir peserta didik (C4, C5, dan C6), salah satu penyebabnya adalah penggunaan buku pelajaran yang kebanyakan (96.35\%) pertanyaan didasarkan pada taksonomi Bloom dan dikelompokkan sebagai masalah $\mathrm{C} 1, \mathrm{C} 2$ dan $\mathrm{C} 3$.

Soal HOTS yang meliputi ranah menganalisis, menilai, dan mengkreasi memiliki keterkaitan satu dengan yang lainnya terutama dalam mengembangkan keterampilan berpikir. Menurut (Suswandari, 2017) kemampuan memecahkan masalah tertentu hanya dapat dilakukan bila sudah menguasai cara menganalisis yaitu teknik membandingkan berbagai alternatif pemecahan masalah dari berbagai segi. Gambaran umum butir soal yang dianalisis dapat dilihat pada Gambar 2 .

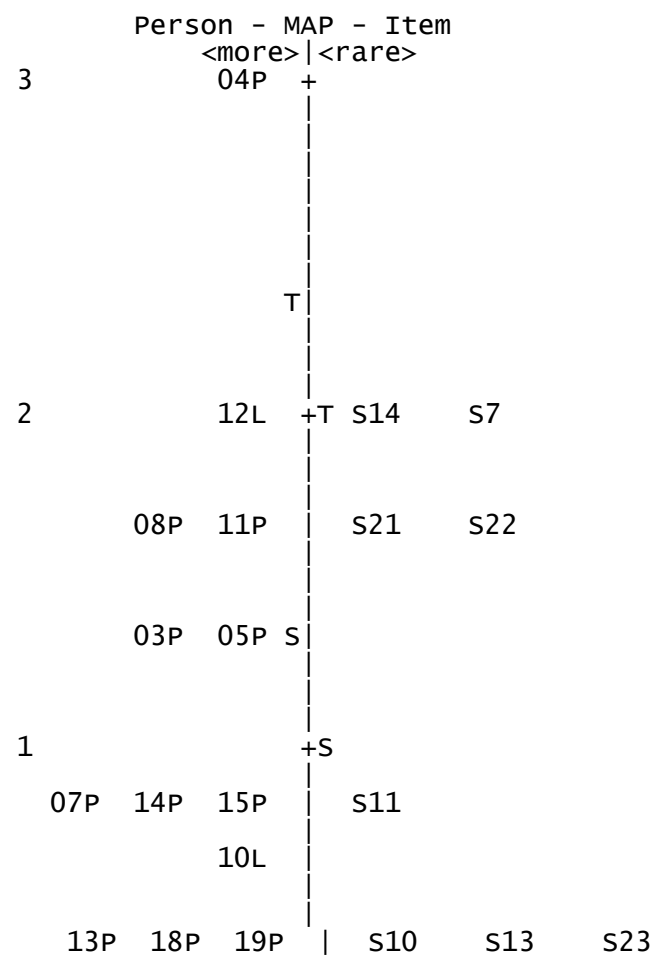




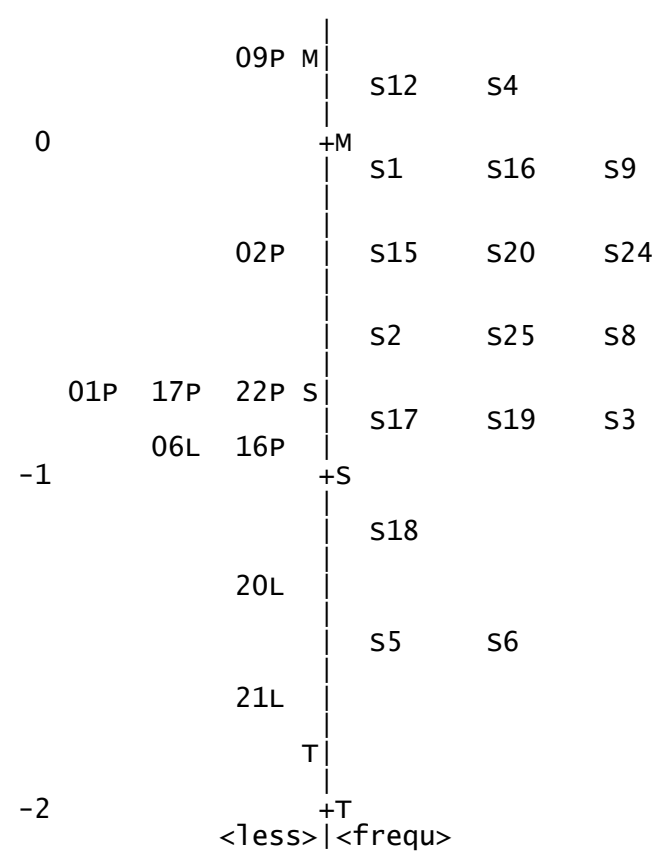

Gambar 2. Gambaran Umum Butir Soal yang Dianalisis

Gambar 2 mengambarkan sebaran kemampuan dari 22 orang mahasiswa dan sebaran tingkat kesukaran soal dengan skala yang sama. Terlihat bahwa ada seorang mahasiswa yang memiliki kemampuan yang sangat tinggi yaitu mahasiswa dengan kode 04P. Nilai logit dari mahasiswa ini adalah +3 logit. Mahasiswa tersebut juga berada di luar batas dua Standar Deviasi (SD) yang ditandai dengan T. Hal ini menunjukkan bahwa mahasiswa ini memiliki kecerdasan tinggi yang berbeda (outlier) dari kelompok yang diuji. Mahasiswa yang memiliki kemampuan paling rendah yaitu dengan kode 21L dengan nilai logit lebih kecil dari 1 logit, namun masih berada pada daerah antara $1 \mathrm{SD}$ dan $\mathrm{T}$.

Kemampuan mahasiswa dalam menyelesaikan soal HOTS juga berpengaruh terhadap prestasi belajar mahasiswa. Mahasiswa yang memiliki kemampuan yang sangat tinggi dalam menyelesaikan soal HOTS tersebut juga memiliki prestasi akademik yang lebih baik dibandingkan dengan mahasiswa yang lainnya. Hal ini sejalan dengan penelitian (Tanujaya, Mumu, \& Margono, 2017) bahwa kedua variabel tersebut (HOTS dan Prestasi akademik) memiliki nilai korelasi yang tinggi $(\mathrm{r}=$ $0,814)$ dan persamaan regresi yaitu $2,105+$ 0,017, menunjukkan bahwa terdapat hubungan yang signifikan antara HOTS dengan prestasi akademik mahasiswa.

Gambar 2 juga menunjukkan bahwa soal S14 dan S7 memiliki tingkat kesukaran paling tinggi yang ditunjukkan dengan nilai logit +2 logit. Soal ini menunjukkan mahasiswa yang dapat mengerjakan dengan benar kemungkinan sebanyak 1 orang mahasiswa yaitu 04P. Soal S5 dan S6 memiliki tingkat kesulitan paling rendah yaitu memiliki nilai logit di bawah -1 logit 
dan kemungkinan semua mahasiswa dapat mengerjakan soal ini dengan benar. Dari hasil tersebut terlihat bahwa tidak ada soal yang outlier. Ada soal-soal yang memiliki tingkat kesukaran yang sama, salah satunya adalah S14 dan S7 yang memiliki nilai +2 logit.

Tabel 3. Rata-rata logit Mahasiswa dan Soal

\begin{tabular}{cc}
\hline Variabel & Rata-rata logit $(\mathbf{S D})$ \\
\hline Mahasiswa & $0,47(1,40)$ \\
Soal & $0,00(0,99)$ \\
\hline
\end{tabular}

Gambar 2 dan Tabel 3 menunjukkan bahwa rata-rata logit (M) mahasiswa yaitu 0,47 lebih besar dari pada rata-rata logit soal yaitu 0,00 . Hal ini menunjukkan bahwa pada dasarnya rata-rata tingkat kemampuan mahasiswa dalam mengerjakan soal HOTS lebih tinggi dari pada rata-rata tingkat kesulitas soal yang diberikan. Menurut (Tajudin \& Chinnappan, 2016) bahwa peserta didik perlu diberikan soal-soal dalam level HOTS agar dapat terlatih mengembangkan kemampuan kognitif mereka sehingga dapat bersaing dalam TIMSS. Mahasiswa yang kesulitan dalam menjawab biasanya kurang latihan mengerjakan soal-soal. Mahasiswa perlu dilatih mengerjakan soal latihan selama perkuliahan berlangsung. Sebagaimana menurut (Kusuma, Undang, Abdurrahman, \& Suyatna, 2017) bahwa pemberian soal HOTS secara bertahap yang dikembangkan oleh pengajar dapat meningkatkan keterampilan berpikir.

\section{KESIMPULAN DAN SARAN}

Dari hasil penelitian dapat disimpulkan bahwa bahwa kemampuan mahasiswa dalam menyelesaikan soal tingkat tinggi masih rendah terutama pada soal $\mathrm{C} 4$ dan $\mathrm{C} 5$ dapat dilihat dari hasil penelitian menunjukkan bahwa rata-rata nilai mahasiswa dalam menyelesaikan soal C4 yaitu 53,18, soal C5 yaitu 52,27 sedangkan soal C6 yaitu 68,83 dengan Rerata 57,27 \pm SD 16,70 berada dalam katagori baik. Selain itu, pemodelan Rasch menunjukkan bahwa soal nomor 14 dan nomor 7 yaitu soal C4 (analisis) memiliki tingkat kesukaran paling tinggi untuk diselesaikan mahasiswa. Soal nomor 5 dan nomor 6 yaitu C6 (mencipta) memiliki tingkat kesulitan paling rendah. Secara keseluruhan, rata-rata tingkat kemampuan mahasiswa dalam mengerjakan soal HOTS lebih tinggi dari pada rata-rata tingkat kesulitas soal yang diberikan

Adapun saran berdasarkan hasil penelitian yang dilakukan yaitu dalam pengukuran kemampuan mahasiswa dalam menyelesaikan soal HOTS sebaiknya menggunakan soal essai sebagai pelengkap selain soal pilihan ganda. Soal essai dimaksudkan untuk menghindari kemungkinan menebak jawaban dari soal yang diberikan. Kemampuan mahasiswa dalam menyelesaikan soal HOTS tidak terlepas dari penerapan pembelajaran yang 
dilakukan. Oleh karena itu sangat penting untuk memilih model pembelajaran yang tepat selama pelaksanaan pembelajaran.

\section{DAFTAR PUSTAKA}

Kusuma, M., Undang, R., Abdurrahman, \& Suyatna, A. (2017). The Development of Higher Order Thinking Skill (Hots) Instrument Assessment In Physics Study. IOSR Journal of Research \& Method in Education (IOSR-JRME), 7(1), 26-32.

Pangkali, T., Sinon, I., \& Widyaningsih, S. (2016). Penerapan Model Kooperatif Tipe TPS terhadap Hasil Belajar Kognitif dan Aktivitas Peserta Didik pada Materi Gelombang Mekanik Kelas XI IPA SMA Negeri 1 Kabupaten Sorong. Jurnal Ilmiah Pendidikan Fisika Al-BiRuNi, 5(2), 173-182.

Retno, U. (2011). Taksonomi Bloom. Tangerang: Pusdiklat KNKP.

Riduwan. (2011). Skala Pengukuran VariabelVariabel Penelitian. Bandung: Alfabeta.

Sophiaraja, K. (2017). Profil Soal IPA Pada Penilaian Akhir Semester Genap SMP Kabupaten Bantul Tahun Ajaran 2016/2017 Berdasarkan Perspektif High Order Thinking Skill (HOTS). Surakarta: Universitas Muhammadiyah Surakarta.

Sudijono, A. (2013). Evaluasi Pendidikan. Jakarta: PT Raja Grafindo Persada.

Suharsimi. (2009). Dasar-Dasar Evaluasi Pendidikan. Jakarta: Bumi Aksara.

Suswandari, M. (2017). Selayang Pandang Implikasi Aliran Pendidikan Klasik. Jurnal Komunikasi Pendidikan, I(1), 33-44.

Tajudin, N., \& Chinnappan, M. (2016). The Link between Higher Order Thinking Skills, Representation and Concepts in Enhancing TIMSS Tasks. International Journal of Instruction, 9(2), 199-214.

Tanujaya, B., Mumu, J., \& Margono, G. (2017). The Relationship Between Higher Order Thinking Skills and Academic Performance of Student In Mathematics Instruction. International Education Studies, 10(11), 78-85.

Tanujaya, B., Prahmana, R. C., \& Mumu, J. (2017). Mathematics instruction, problems, challenges and opportunities: a case study in Manokwari Regency,
Indonesia. World Transactions on Engineering and Technology Education, 15(3), 287-291. 